Immunobiol., vol. 169, pp. 447-454 (1985)

Max-Planck-Institut für Immunbiologie, Freiburg, Federal Republic of Germany

\title{
Recombinant Human Interleukin 2 Directly Provides Signals for the Proliferation and Functional Maturation of Murine B Lymphocytes
}

\author{
H. MOLL, F. EMMRICH, and M. M. SIMON
}

Received September 27, 1984 - Accepted October 25, 1984

\begin{abstract}
In this study the effect of recombinant human interleukin 2 (rec.hIL-2) on the proliferation and maturation of $B$ lymphocytes was investigated. It was found that the presence of rec.hIL 2 results in proliferation of mitogen (LPS)-activated B cell blasts. In addition, it is shown that highly enriched murine B cells can be induced by rec.hIL-2 to proliferate and to develop into antibody-secreting cells (PFC) in the presence of antigen (SRBC). When tested for its effect on B cell preparations enriched for resting (small) or activated (blasted) B lymphocytes, it was found that rec.hIL 2 provides signals for both B cell populations to develop into PFC. In contrast, induction of proliferation by the same lymphokine source was only seen in blasted $B$ cells. The data indicate that IL 2 is involved in the generation of B effector cells by directly acting on their precursors thereby providing differentiation as well as proliferation signals.
\end{abstract}

\section{Introduction}

Interleukin 2 (IL 2) is well recognized as a proliferation factor for activated $\mathrm{T}$ lymphocytes (1), but there are indications that this lymphokine may also play a role in the growth and/or maturation of non- $T$ cell populations $(2,3)$. In this respect, it is still a controversial issue whether IL 2 is capable of directly promoting the activation of B lymphocytes. In order to obtain more conclusive evidence, it is obligatory to use pure sources of IL 2 which do not contain additional lymphokine activities and a responder B cell population depleted of contaminating $T$ cells. In this study we, therefore, compared the effect of recombinant human IL 2 (rec.hIL 2,

\footnotetext{
Abbreviations: $\operatorname{ConA}=$ Concanavalin A; EL-4-SN = Supernatant of PMA-stimulated EL-4 tumor cells; IL $2=$ interleukin $2 ; L P S=$ lipopolysaccharide; $P F C=$ antibody-secreting cell; $P M A=$ phorbol myristate acetate; rec. $h I L-2=$ human interleukin 2, expressed in E.coli by recombinant DNA techniques; $S R B C=$ sheep red blood cells; TCGF $=\mathrm{T}$ cell growth factor(s) including interleukin $2 ;{ }^{3} H-T d R=$ tritiated thymidine.
} 
Sandoz Forschungsinstitut, Wien, Austria) with that of another lymphokine source, i.e. PMA-induced EL-4 thymoma supernatant (EL-4-SN), on the proliferation of $\mathrm{B}$ lymphocytes and the generation of antibody producing cells (PFC) from precursor $\mathrm{B}$ cells responding to sheep red blood cells $(\mathrm{SRBC})$. The data demonstrate that IL 2 directly promotes the maturation of B lymphocytes.

\section{Materials and Methods}

\section{Mice}

Mice of the strain $\mathrm{C} 57 \mathrm{Bl} / 6$ (B6) were obtained from the animal colony maintained at the Max-Planck-Institut für Immunbiologie, Freiburg, FRG, and were used between 6 weeks and 3 months of age.

\section{Cell separation techniques}

B cells were isolated from erythrocyte-free B6 spleen cell suspensions by treatment with anti-Thy-1.2 antiserum (Olac) and guinea pig complement (Behring), followed by another treatment with anti-Lyt-1.2 plus anti-Lyt-2.2 antisera and selected rabbit complement (4). $\mathrm{B}$ cells selected by this protocol completely lacked proliferative responses to Concanavalin A (ConA). This splenic B cell population was separated on the basis of size by Percoll (Pharmacia) density centrifugation to obtain the large (blasted) and the small (resting) B cell subsets (5).

\section{Cultures for proliferative and PFC responses}

All cultures were performed in Dulbecco's modified Eagle's medium (DMEM) supplemented with $2 \times 10^{-5} \mathrm{M} 2$-mercaptoethanol, kanamycin $(100 \mu \mathrm{g} / \mathrm{ml})$, tylosine $(10 \mu \mathrm{g} / \mathrm{ml})$, glutamine $(2 \mathrm{mM})$ and $10 \%$ selected fetal calf serum. Cultures were set up in a total volume of $200 \mu \mathrm{l}$ in round bottom microtiter plates (Nunc, 163220, Wiesbaden, FRG) and were kept in a $7 \% \mathrm{CO}_{2}$-incubator. For the detection of proliferative responses, $1 \times 10^{5} \mathrm{~B}$ cells/well were cultured for 3 days in the presence or absence of lymphokine sources and $1.25 \mu \mathrm{Ci}$ tritiated thymidine $\left({ }^{3} \mathrm{H}-\mathrm{TdR}\right)$ per well was added for the last $4 \mathrm{~h}$. Cells were harvested onto filter strips using an automatic cell harvester and counted in a liquid scintillation $\beta$-counter. For the detection of PFC responses, $3 \times 10^{5} \mathrm{~B}$ cells/well and $5 \times 10^{4} \mathrm{SRBC} /$ well were cultured in the presence or absence of lymphokine sources. After 5 days of incubation, cultures were tested for direct SRBC-specific PFC as described (6).

Mitogen-induced lymphoblasts were generated by incubating either $12 \times 10^{6}$ enriched B cells in $6 \mathrm{ml}$ with $10 \mu \mathrm{g} \mathrm{LPS} / \mathrm{ml}$ for $72 \mathrm{~h}$ or $12 \times 10^{6}$ nylon wool-purified T cells $/ 6 \mathrm{ml}$ with $5 \mu \mathrm{g} \mathrm{ConA} / \mathrm{ml}$ for $48 \mathrm{~h}$. For the detection of proliferative responses, $6 \times 10^{4}$ mitogen-activated cells/well were cultured for 2 days in the presence or absence of lymphokine sources and ${ }^{3} \mathrm{H}-\mathrm{TdR}$ was added for the last $4 \mathrm{~h}$.

\section{Lymphokine sources}

a) EL-4 supernatant (EL-4-SN) was obtained by stimulating a cloned subline of EL-4 thymoma with $10 \mathrm{ng} / \mathrm{ml}$ phorbol myristate acetate (PMA) as described elsewhere (7).

b) recombinant human interleukin 2 (rec.hIL 2) was kindly provided by Dr. M. WRANN, Sandoz Forschungsinstitut, Wien, Austria.

The lymphokine sources were tested for their TCGF activity by incubating serial dilutions (50-0.02 ng rec.hIL 2, 50-0.38\% EL-4-SN) with $2 \times 10^{3}$ cells of the lymphokine-dependent cytotoxic T cell line CTLL 2 (kindly provided by Dr. GILLES) in a total volume of $200 \mu \mathrm{l}$ in round bottom microtiter plates. After $20 \mathrm{~h}$ of incubation, $1.25 \mu \mathrm{Ci}{ }^{3} \mathrm{H}-\mathrm{TdR} /$ well was added for 
the last $4 \mathrm{~h}$. Cells were harvested onto filter strips using an automatic cell harvester and counted in a liquid scintillation $\beta$-counter. The data were subjected to probit analysis (8), and the activity was expressed in units of TCGF $(1 \mathrm{U}=100 \mathrm{pg}$ rec.hIL $2 / 0.2 \mathrm{ml}$, which allow half maximal proliferation of $2 \times 10^{3}$ CTLL-2 after $24 \mathrm{~h}$ ).

\section{Absorption of lymphokines}

IL 2 depletion of lymphokine sources was performed by incubating $2 \times 10^{7}$ CTLL- 2 cells with either rec.hIL 2 or EL-4-SN (containing the amount of 1000 U IL-2) for 4-6 hours. The absorbed supernatants were collected after pelleting the cells and were functionally compared to the untreated samples on the basis of their original IL 2 content. When retested on CTLL-2, both absorbed lymphokine sources lacked detectable IL 2 activity.

\section{Results and Discussion}

Proliferation of $\mathrm{B}$ cells was measured by ${ }^{3} \mathrm{H}-\mathrm{TdR}$ incorporation, and differentiation into immunoglobulin-secreting cells was determined by testing for SRBC-specific plaque-forming cell responses (PFC). A thoroughly enriched B cell population was obtained by treating erythrocyte-free spleen cells with $\mathrm{T}$ cell-specific antisera and complement as described in Materials and Methods. In order to estimate the residual portion of functional $\mathrm{T}$ cells, we tested the selected $\mathrm{B}$ cell population for proliferative responses to the $\mathrm{T}$ cell-specific mitogen ConA. It could be

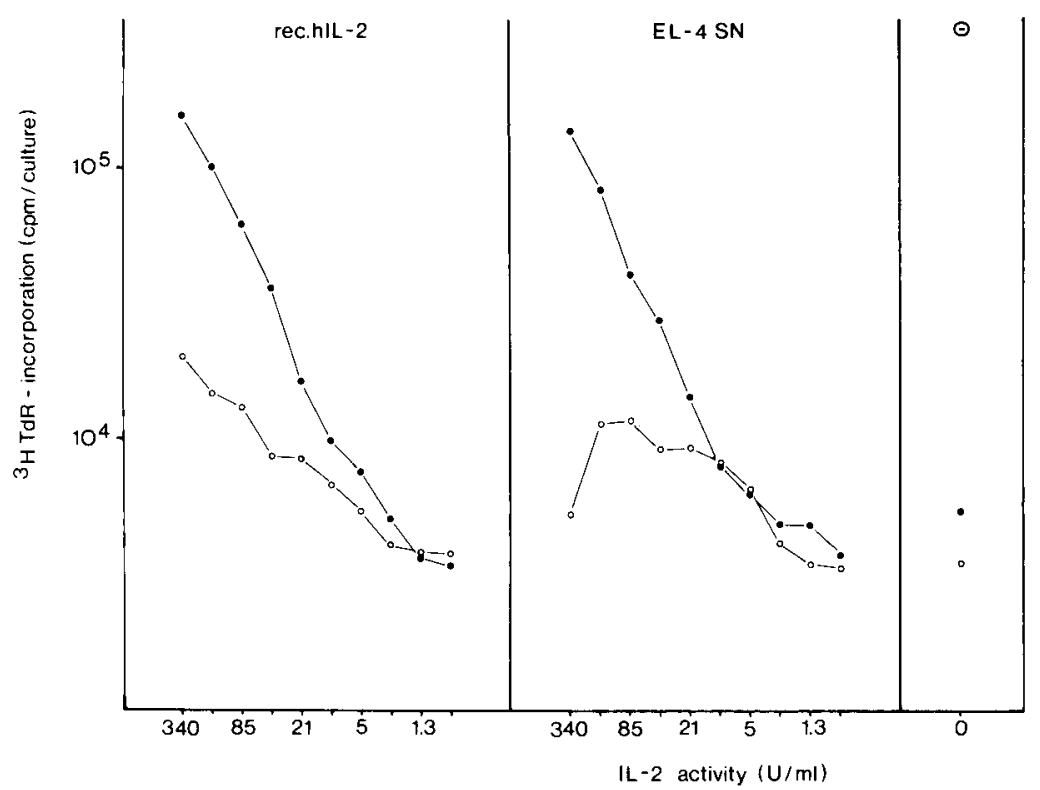

Fig. 1. Responsiveness of mitogen-induced T or B lymphoblasts to either rec.hIL 2 or EL-4-SN. Graded amounts of lymphokine sources were titrated into cultures containing either ConAactivated T cells $(-)$ or LPS-activated $\mathrm{B}$ cells $(\mathrm{O})$. The proliferative responses were determined after an incubation period of $48 \mathrm{~h}$ as described in Materials and Methods. 
demonstrated that the $\mathrm{T}$ cell-deprived $\mathrm{B}$ lymphocyte population completely lacked reactivity to ConA. Since mitogen-induced proliferation in these cultures was significantly enhanced only upon addition of $0.5 \%$ nylon wool-purified $\mathrm{T}$ cells, we estimated the amount of contaminating $\mathrm{T}$ cells in the B cell population studied to be below this threshold (data not shown).

To examine whether IL 2 induces proliferative responses in polyclonally activated $\mathrm{T}$ and $\mathrm{B}$ cell populations, graded amounts of lymphokines (rec.hIL 2 or EL-4-SN) were titrated into cultures containing either nylon wool-purified T cells which had been preactivated with ConA or selected $B$ cells which had been preactivated with LPS (Fig. 1). The data clearly demonstrate that $B$ lymphoblasts proliferated dose-dependently in response to rec.hIL 2, though to a somewhat lower degree when compared to $T$ lymphoblasts. Similar dose response curves for proliferation were obtained for T cell blasts responding to either rec.hIL 2 or EL-4-SN. On the contrary, the growth of $\mathrm{B}$ cell blasts was inhibited at higher concentrations of EL-4-SN which may be due to non-IL 2 components present in this factor source (see below).

We next asked whether IL 2 is also involved in the generation of immune responses from antigen-activated $\mathrm{B}$ lymphocytes. For this purpose, the

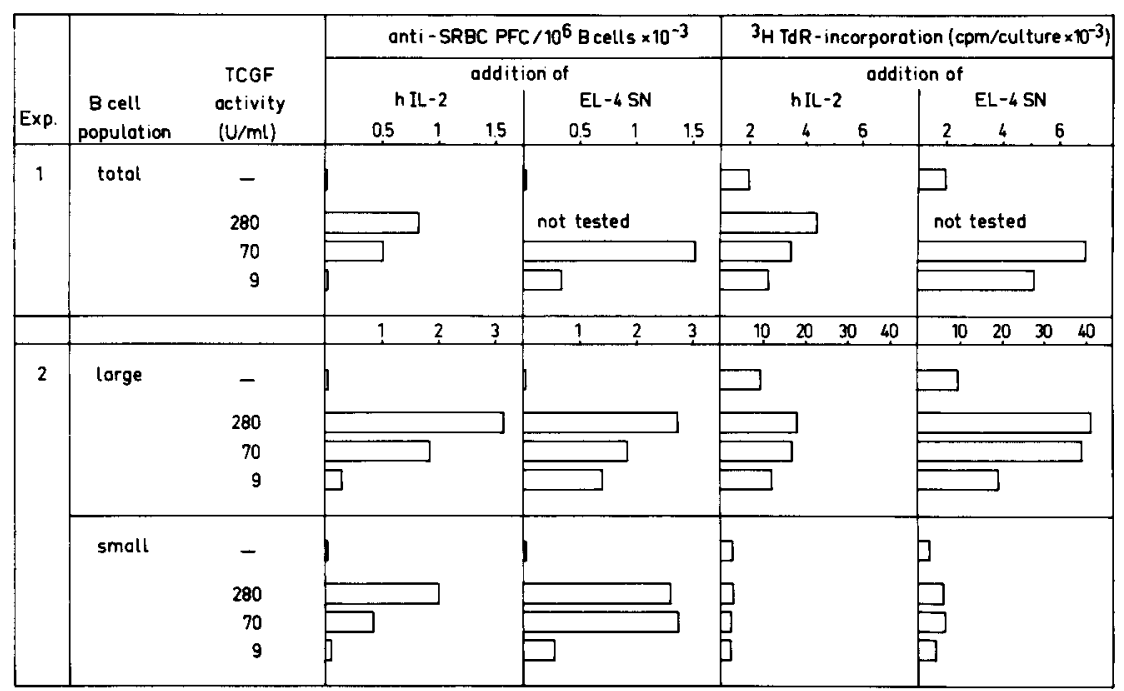

Fig. 2. Effect of rec.hIL 2 and EL-4-SN on the proliferation and differentiation of either unfractionated B cell or of small or large B lymphocytes. For the detection of SRBC-specific antibody production, enriched $T$ cell depleted $B$ cells and SRBC were incubated in graded concentrations of lymphokine sources (rec.hIL 2, EL-4-SN) which had been adjusted to contain the same amount of IL 2 (as described in Materials and Methods). The cultures were tested for direct SRBC-specific PFC on day 5. For the detection of proliferative responses, B cells and graded amounts of lymphokine sources were incubated in the absence of SRBC and ${ }^{3} \mathrm{H}-\mathrm{TdR}$ incorporation was measured on day 3. The first lines of Exp. 1 and Exp. 2 show the responsiveness of control cultures lacking external factor sources. 
appropriate B cell populations - either unfractionated or previously separated for small (resting) and large (activated) B lymphocytes on a Percoll density gradient (5) - were incubated with graded amounts of lymphokine sources which had been adjusted to comparable IL 2 concentrations (arbitrary units, as described in Materials and Methods; Fig. 2). SRBC were included in the cultures for PFC generation but not in those for proliferative responses (see below). In the presence of both rec.hIL 2 and EL-4-SN, unseparated $\mathrm{B}$ cells showed significant antigen-independent proliferation and SRBC-specific PFC responses the level of which corresponded with the concentration of IL 2 in culture. In contrast, only marginal immune reactivities were observed in control cultures lacking external factors (Fig. 2, Exp. 1). When populations enriched for either B cell blasts or small B cells were tested separately under similar conditions, comparable PFC numbers were seen in both populations in response to either rec.hIL 2 or EL-4-SN (Fig. 2, Exp. 2). In contrast, proliferation was only induced in B cell blasts but not in small $B$ cells by the addition of either rec.hIL 2 or EL-4-SN, respectively. It is important to emphasize that the lymphokine-driven proliferative responses of both selected $B$ cell populations were not altered by the addition of antigen (SRBC) to the cultures (data not shown). The data, therefore, reveal that rec.hIL 2 is capable of providing signals for the generation of PFC from both small and large B cells and, in addition, triggers B cell blasts but not small B cells for proliferation. The finding that IL 2 cannot induce replication of small, resting B cells even in the presence of antigen but drives them to maturation into PFC is similar to that described by MELCHERs et al. (9) for a $T$ helper cell-derived B cell replication and maturation factor(s). In this study, it was shown that the factor-induced antibody production in small B cells was accompanied by a loss of their capacity to replicate.

It should be noted that the E.coli-derived rec.hIL 2 preparation used in this study contains a minute amount of bacterial lipopolysaccharide $(0.27$ ng LPS/mg IL-2 as determined in the limulus assay by Sandoz, Wien). Since the optimal LPS quantities required for a polyclonal B cell activation are some orders of magnitude higher, it is very unlikely that these traces of LPS have a perceptible effect.

It was previously demonstrated that EL-4-SN in addition to IL 2 contains other lymphokine(s) which can deliver activation signals to B lymphocytes (10). It was, therefore, of interest to test whether depletion of IL 2 from rec.hIL 2 and EL-4-SN would abrogate the capacity to activate B cells only in the former but not in the latter lymphokine source. We took advantage of the fact that the IL 2-dependent T cell line CTLL-2 preferentially absorb IL 2 but not unrelated lymphokines by virtue of their specific cell surface receptor (8). Either unabsorbed or IL 2 depleted samples of EL-4-SN and rec.hIL 2 were added to unfractionated B cell cultures set up for proliferative and PFC responses (Fig. 3). As expected, the absorption of IL 2 from rec.hIL 2 sources significantly reduced the effects associated with 


\begin{tabular}{|c|c|c|c|c|c|c|}
\hline \multirow{4}{*}{$\begin{array}{l}\text { treotment } \\
\text { of lymphokine } \\
\text { sources }\end{array}$} & \multirow{4}{*}{$\begin{array}{l}\text { TCGF } \\
\text { activity } \\
\text { (U/ml) }\end{array}$} & \multicolumn{2}{|c|}{ onti-SRBC PFC $/ 10^{6} B$ cells $\times 10^{-2}$} & \multicolumn{3}{|c|}{$3^{3} \mathrm{HTdR}$ - incorporation (cpm/culture $\times 10^{-3}$ ) } \\
\hline & & \multicolumn{2}{|c|}{ addition of } & \multicolumn{3}{|c|}{ addition of } \\
\hline & & hIL-2 & EL- $4 \mathrm{SN}$ & \multicolumn{2}{|c|}{ nIL-2 } & $E L-45 \mathrm{~N}$ \\
\hline & & $\begin{array}{llll}0.5 & 1 & 1.5 & 2\end{array}$ & $0.5 \quad 1 \quad 1.5 \quad 2$ & .4 & 6 & $2 \quad 4 \quad 6$ \\
\hline \multirow{4}{*}{ (a) none } & - & & \multirow[b]{2}{*}{ not tested } & \multicolumn{2}{|l|}{$\square$} & $\square$ \\
\hline & 340 & $=$ & & \multicolumn{2}{|c|}{$\square$} & not tested \\
\hline & $\begin{array}{l}85 \\
21\end{array}$ & $\square$ & $\square$ & \multicolumn{2}{|l|}{$\Longrightarrow$} & $\Longrightarrow$ \\
\hline & 5 & & & & $\square$ \\
\hline \multirow{3}{*}{$\begin{array}{l}\text { (b) absorption } \\
\text { on CTLL-2 }\end{array}$} & 85 & & $\square$ & \multicolumn{2}{|l|}{$\square$} & $\square$ \\
\hline & 21 & & 3 & \multirow{2}{*}{\multicolumn{2}{|c|}{ 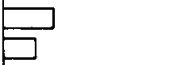 }} & \multirow{2}{*}{$\square$} \\
\hline & 5 & & & & & \\
\hline
\end{tabular}

Fig. 3. Effect of either unabsorbed or IL 2-depleted samples of rec.hIL 2 and EL-4-SN on the proliferation and antibody formation of unselected B cells. The concentrations of the lymphokine sources (rec.hIL 2, EL-4-SN) to be absorbed with CTLL-2 were adjusted to contain the same amount of IL 2 as the untreated samples (as described in Materials and Methods). After depletion of IL 2, both lymphokine sources were titrated to cultures of unselected $\mathrm{B}$ cells. In addition, SRBC were included in the cultures for PFC responses. Proliferation and PFC responses were tested as described in the legend to Fig. 1 . The first line shows the responsiveness of control cultures lacking external factor sources.

B cell activation (growth and PFC formation). In contrast, removal of IL 2 from EL-4-SN had only marginal effects on its capability to induce B cell growth and differentiation. These results again emphasize the role of IL 2 in the induction of $\mathrm{B}$ cells and indicates the presence of additional $\mathrm{B}$ cell growth/maturation factor(s) in EL-4-SN which have been described before to provide triggering signals in humoral immune responses (10). In addition, the lack of activities in IL 2 depleted samples of rec.hIL 2 argues against the stimulatory effect being mediated by contaminating irrelevant proteins within the preparation used. This is also substantiated by the finding that a mock-IL 2 preparation had no effect on the generation of $B$ cell responses (EMMRICH, unpublished results).

The results given here demonstrate that murine $\mathrm{B}$ lymphocytes presensitized in vitro by either mitogen or antigen as well as in vivo derived enriched B cell blasts are responsive to rec.hIL 2 which is in line with a recent study by ZUBLER et al. (11). Similar results have recently been obtained by our group (12) and others $(11,13)$ also in the human system showing that the same source of recombinant hIL $2(11,12)$ or a sample of affinity purified IL 2 (13) can induce proliferation and immunoglobulin secretion in polyclonal preactivated $\mathrm{T}$ cell-deprived $\mathrm{B}$ cell populations. This indicates that in the presence of antigen or mitogen the lymphokine signal provided by IL 2 is sufficient for the development of $B$ effector cells from their precursors. Similar effects on the activation of B lymphocytes have been described before for $\mathrm{T}$ cell-derived soluble mediators distinct from IL 2 (10). The combined data, therefore, suggest the existence of distinct lymphokines with the properties of growth and maturation factors for $\mathrm{B}$ 
cells. However, the question whether they act on the same or different B lymphocyte subsets remains to be answered. In addition, the mode of action of IL 2 on the individual target cell in both small and large B cell populations is uncertain, but the fact that IL 2 can induce PFC responses in both populations and proliferation in the activated lymphocyte subset indicates that the same lymphokine can provide both growth and differentiation signals. Because of the lack of an appropriate monoclonal antibody we could not yet demonstrate the expression of IL 2 receptor molecules on the B cell populations directly. However, we (12) and others (13) have recently shown in the human system that the monoclonal antibody anti-Tac (14) with specificity for the IL 2 receptor on T cells also stained activated B cells. This was indicated before for rat B lymphoblasts which were stained by a putative mouse anti-rat-IL 2 receptor antibody (15), and has now also been confirmed for murine $B$ cells by ZUBLER et al. using a rat anti-mouse monoclonal antibody with similar specificity for the IL 2 receptor $(11$, and personal communication). The combined data, therefore, allow the conclusion that IL 2 provides one of the essential signals to the B cell during development of humoral immune responses.

\section{Acknowledgements}

We would like to thank Dr. HögENAUER, Sandoz Forschungsinstitut, Wien, for kindly providing us with recombinant human IL 2. We also thank Prof. K. EICHMANN for discussion and Ms N. LEIBROCK for excellent secretarial assistance.

\section{References}

1. SMITH, K. A.. 1980. T-cell growth factor. Immunol. Rev. 51: 337.

2. Henney, C. S., K. Kuribayashi, D. E. Kern, and S. Gillis. 1981. Interleukin 2 augments natural killer cell activity. Nature 291: 335.

3. MALEK, T. R., R. J. RobB, and E. M. SHeVACH. 1983. Identification and initial characterization of a rat monoclonal antibody reactive with the murine interleukin 2 receptor-ligand complex. Proc. Natl. Acad. Sci. USA 80: 5694.

4. Moll, H., K. EICHMANN, and M. M. SIMON. 1985. Immunoregulation by mouse T cell clones. II. The same H-Y-specific T helper clone can provide help for the generation of cytotoxic lymphocytes and of antibody secreting cells. Immunology, in press.

5. Ratcliffe, M. J. H., and M. H. Julius. 1982. H-2-restricted T-B cell interactions involved in polyspecific B cell responses mediated by soluble antigen. Eur. J. Immunol. 12: 634 .

6. Jerne, N. K. and A. A. Nordin. 1963. Plaque formation in agar by single antibodyproducing cells. Science 140: 405.

7. Farrar, J. J., W. Benjamin, M. Hilfiker, M. Howard, W. Farrar, and J. FullerFARRAR. 1982. The biochemistry, biology, and role of interleukin 2 in the induction of cytotoxic $T$ cell and antibody-forming B cell responses. Immunol. Rev. 63: 219.

8. Gillis, S., M. M. FerM, W. OU, and K. A. SMITH. 1978. T cell growth factor parameter of production and a quantitative microassay for activity. J. Immunol. 120: 2027.

9. Melchers, F., J. Andersson, W. Lernhardt, and M. H. Schreier. 1980. H-2 unrestricted polyclonal maturation without replication of small B cells induced by antigen-activated T cell help factors. Eur. J. Immunol. 10: 679. 
10. Howard, M., J. Farrar, M. Hilfiker, B. Johnson, K. Takatsu, T. Hamaoka, and W. E. PAUL. 1982. Identification of a T-cell derived B-cell growth factor distinct from interleukin-2. J. Exp. Med. 155: 914.

11. Zubler, R. H., J. W. Lowenthal, F. Erard, N. Hashimoto, R. Devos, and H. R. MACDONALD. 1984. Activated B cells express receptors for and profilerate in response to pure Interleukin 2. J. Exp. Med. 160: 1170.

12. Emmrich, F., H. MOLl, and M. M. SimON. 1984. Recombinant human interleukin 2 acts as a $\mathrm{B}$ cell growth and differentiation promoting factor. Immunobiol., in press.

13. Tsudo, M., T. UCHIYAMA, and H. UCHINO. 1984. Expression of Tac antigen on activated normal human B cells. J. Exp. Med. 160: 612.

14. Leonard, W. J., J. M. Depper, R. J. Robb, T. A. Waldmann, and W. C. Greene. 1983. Characterization of the human receptor for T-cell growth factor. Proc. Natl. Acad. Sci. USA 80: 6957.

15. Osawa, $H$. and T. Diamantstein. 1983. The characteristics of a monoclonal antibody that binds specifically to rat $\mathrm{T}$ lymphoblasts and inhibits IL-2 receptor functions. J. Immunol. 130: 51.

Dr. M. M. SIMON, Max-Planck-Institut für Immunbiologie, Postfach 11 69, Stübeweg 51, D-7800 Freiburg, F.R.G. 